\title{
Effects of Horticultural Activities and Flower Tea Drinking Based on Reminiscent Storytelling on Demented Elders' Cognitive and Emotional Functions
}

\author{
Jong-Hee Lee, Hyun-Seok Choi, Suk-Young Yun*, Byung-Jin Choi, and Eun-Jin Jang \\ Department of Horticulture, The Graduate School, Catholic University of Daegu 38430, South Korea
}

\begin{abstract}
This study was conducted in order to examine the effects of horticultural activities and flower tea drinking based on reminiscent storytelling on demented elders' cognitive and emotional functions. For these an purposes, the program was executed 35 elders divided four groups at the elders institutionalized at B Facility through 10 sessions during the period from 10 March to 14 July in 2015. As a result first, in the test of pretreatment homogeneity among the groups, no significant difference was observed among the four groups, so they were considered homogeneous. As to difference between before and after the program, cognitive functions were improved significantly after the treatment in the experimental group with both horticultural activities and flower tea drinking $(p=.039)$. Among the emotional functions, self-esteem was significantly different in the experimental group with only horticultural activities $(p=.040)$, the experimental group with only flower tea drinking $(p=.005)$, and the experimental group with both horticultural activities and flower tea drinking $(p=.024)$. Life satisfaction was significantly different only in the experimental group with both horticultural activities and flower tea drinking $(p=.005)$. Ego integrity was significantly different in the experimental group with only horticultural activities $(p=.011)$ and the experimental group with both horticultural activities and flower tea drinking $(p=.005)$. Therefore, the experimental group with both horticultural activities and flower tea drinking were improved significant that all the items of cognitive and emotional functions.
\end{abstract}

Keywords: ego integrity, life satisfaction, olfactory effects, self esteem, visual effects

\section{Introduction}

The elderly population is rapidly increasing along with the average lifespan in the Korean society today. The elderly population has reached $13.1 \%$, which is 6.62 million, in 2015, which will reach approximately 12.69 million by 2030 that is $24.3 \%$ of the entire population, entering fully into a super-aging society (KOSIS, 2014). Upon entering a super-aging society, the number of patients with senile dementia aged 65 or above is estimated at 685,739 in 2016 and will double every 20 years by 2050 to 840 thousand in 2020, 1.27 million in 2030, and 2.71 million in 2050 (MOHW, 2012).

Dementia is an organic mental disorder in which cognitive functions in various fields such as memory, language and judgment are degenerated by many external factors like acquired trauma or disease (Lee et al., 2002). Thus, there is emphasis on reminiscence therapy that is a therapeutic activity of psychosocial intervention as a nonmedical intervention 
(non-drug treatment) aside from medical intervention (drug treatment) (Cho, 2008).

Sheridan (1991) argued that it is extremely important for reminiscence in reminiscence therapy to not just remember a certain event but also bring back the emotions or feelings of the time by recalling a situation associated with the event, which is useful for dementia patients. Park (2004) claimed that horticultural programs implementing reminiscence therapy are effective for promoting cognitive skills and memory of elders with dementia, and Park (2007) stated that group reminiscence programs positively affect orientation of elders with dementia, thereby showing effect in maintaining and promoting cognitive functions. Furthermore, Kim (2015) claimed that horticultural therapy applying structural reminiscence is effective in improving the emotional function of elders with dementia.

Smell stimulates associations of memory for people (Kim, 1997). All human senses recall memories, but olfactory sense and gustatory sense particularly serve as a strong catalyst for reminiscence, and one can recall memory much more quickly when he or she smells something related to the reminiscence (Hyun, 1999). Moreover, flower tea contains at least 10 times more antioxidant ingredients like polyphenol and flavonoid than vegetables and fruits (Dailysisa, 2013), and polyphenol is especially effective in preventing brain diseases like senile dementia or Parkinson's disease (McAnulty et al., 2004).

Therefore, this study is conducted to determine the effects of carrying out horticultural activities applying storytelling based on reminiscence with flower tea drinking programs stimulating olfactory and gustatory senses on the cognitive and emotional functions of elders with dementia.

\section{Research Method}

\section{Research subject}

This study was conducted on elders aged 65 and above diagnosed with dementia who cannot live an independent life among those living in a skilled nursing facility by B Foundation located in D City for chronic geriatric diseases. The control group consisted of 9 subjects ( 3 males and 6 females), the experimental group with horticultural activities consisted of 8 subjects ( 4 males and 4 females), the experimental group with flower tea drinking consisted of 8 subjects ( 8 females), and the experimental group with both horticultural activities and flower tea drinking consisted of 10 subjects (1 male and 9 females), adding up to total 35 subjects.

Characteristics of the subjects by group are as follows. For the control group, the average age was $78.7 \pm 9.6$ and the average cognitive ability Mini-Mental State Examination(MMSE-K) was 20.1 \pm 4 .6. For the experimental group with horticultural activities, the average age was $76.5 \pm 4.4$ and the average cognitive ability was $16.1 \pm 5.4$. For the group with

Table 1. Personal characteristics of subjects.

\begin{tabular}{|c|c|c|c|}
\hline Group & Sex & Age & MMSE-K \\
\hline $\mathrm{C}$ & $\mathrm{M}(3), \mathrm{F}(6)$ & $78.7 \pm 9.6$ & $20.1 \pm 4.6$ \\
\hline $\mathrm{H}$ & $\mathrm{M}(4), \mathrm{F}(4)$ & $76.5 \pm 4.4$ & $16.1 \pm 5.4$ \\
\hline $\mathrm{F}$ & $\mathrm{M}(0), \mathrm{F}(8)$ & $81.1 \pm 6.6$ & $15.4 \pm 3.0$ \\
\hline $\mathrm{HF}$ & $\mathrm{M}(1), \mathrm{F}(9)$ & $82.4 \pm 9.5$ & $16.7 \pm 4.2$ \\
\hline
\end{tabular}

Values are presented mean \pm standard deviation.

$\mathrm{C}=$ Control group; $\mathrm{H}=$ Horticultural activity group; $\mathrm{F}=$ Flower tea group; $\mathrm{HF}=$ Horticultural activity+Flower tea group; MMSE-K, Mini-Mental State Examination. 
flower tea drinking, the average age was $81.1 \pm 6.6$ and the average cognitive ability was $15.4 \pm 3.0$. For the group with both horticultural activities and flower tea drinking, the average age was $82.4 \pm 9.5$ and the average cognitive ability was $16.7 \pm 4.2$ (Table 1).

\section{Experimental design}

This study was conducted by dividing the subjects into the control group, experimental group with horticultural activities, experimental group with flower tea drinking, and experimental group with both horticultural activities and flower tea drinking. All of the control group and the three experimental groups had the cognitive ability (MMSE-K), self-esteem, life satisfaction and ego integrity measured before and after the horticultural activities. The control group was measured at the same point as the experimental groups without horticultural activities (Table 2).

\section{Research tool}

\section{Design of the horticultural activity program}

Before conducting the study, a pretest was carried out to select the material and theme of reminiscence in the process of determining the subjects. Based on the results, materials and themes that stimulate reminiscence were chosen for each session during the horticultural activities and flower tea drinking, thereby establishing a group program for reminiscent storytelling through a series of horticultural activities including the theme and flower tea drinking. This program was restructured according to the objective of this study with reference to previous studies on the effects of horticultural therapy applying reminiscence by Kim (2010) on ego integrity and self-esteem of elders with chronic diseases. Table 3 shows the detailed horticultural activity program. Session 1 used color sand to depict the splendor of a flower palanquin, recalling the day of a new bride getting married by making a terrarium. Session 2 was to recall the memory of moving into a new house while making a tillandsia house. Session 3 was to recall the time when the subjects prepared food for feasts, national holidays and memorial services as they cooked and ate fried magnolia. In Session 4, they dyed handkerchiefs with gardenia and recalled food coloring in yellow, as well as housework like washing and cleaning. Session 5 was recalling the memory of raising bean sprouts as they sowed sprouts, and Session 6 was recalling the times they cooked and ate pan-fried sweet rice cake (hwajeon) with azalea as they made sandwiches with the sprouts they raised themselves. In Session 7, they made a fragrance bag containing medicinal herbs and recalled the time they were sick in childhood and the value of health. In Session 8, they recalled the memory of playing and swimming in the stream in summer while participating in the aquaculture program. In Session 9 they recalled receiving a gift of flowers while making a flower basket, and in Session 10 they made a mini garden with charcoal and recalled straw rope, making soy sauce and giving birth related to charcoal. The flower tea drinking program consisted of showing the types of flower tea in advance and

Table 2. Experimental design.

\begin{tabular}{|c|c|c|c|}
\hline Group & Before-test & Program & After-test \\
\hline $\mathrm{C}$ & $\mathrm{C}_{1}$ & - & $\mathrm{C}_{2}$ \\
\hline $\mathrm{H}$ & $\mathrm{H}_{1}$ & Horticultural activity & $\mathrm{H}_{2}$ \\
\hline $\mathrm{F}$ & $\mathrm{F}_{1}$ & Flower tea & $\mathrm{F}_{2}$ \\
\hline $\mathrm{HF}$ & $\mathrm{HF}_{1}$ & Horticultural activity + Flower tea & $\mathrm{HF}_{2}$ \\
\hline
\end{tabular}

Values are presented mean \pm standard deviation.

$\mathrm{C}=$ Control group; $\mathrm{H}=$ Horticultural activity group; $\mathrm{F}=$ Flower tea group; $\mathrm{HF}=$ Horticultural activity+Flower tea group. 
Table 3. The horticultural activity program based on reminiscent storytelling and flower tea.

\begin{tabular}{|c|c|c|c|c|}
\hline No. & Horticultural activity program & Materials of reminiscent stories & Themes of reminiscence & Flower tea \\
\hline 1 & $\mathrm{O} / \mathrm{T}$ and terrarium & Color sand & $\begin{array}{l}\text { Color-striped Korean jacket, rouge on } \\
\text { the cheeks and the forehead, bride }\end{array}$ & Magnolia tea \\
\hline 2 & Air plants house making & Clay pot & $\begin{array}{l}\text { The day when moving to a new house } \\
\text { for the first time }\end{array}$ & Magnolia tea \\
\hline 3 & Magnolia fries & Magnolia kobus & $\begin{array}{l}\text { Reminiscences of feast food and } \\
\text { memorial service food }\end{array}$ & Magnolia tea \\
\hline 4 & Handkerchief dyeing & $\begin{array}{c}\text { Gardenia jasminoides, Name tag, } \\
\text { Handkerchief }\end{array}$ & $\begin{array}{l}\text { Food coloring in yellow, housework, } \\
\text { washing, cleaning }\end{array}$ & Azalea tea \\
\hline 5 & Sprout seed sowing & Sprout seed & Bean sprout raising & Azalea tea \\
\hline 6 & $\begin{array}{l}\text { Sprout sandwich Pan fried sweet } \\
\text { rice cake with azalea }\end{array}$ & $\begin{array}{l}\text { Rhododendron mucronulatum } \\
\text { Sandwich }\end{array}$ & Rice cake earthenware steamer, feast & Azalea tea \\
\hline 7 & Fragrance bag (medicinal herbs) & Medicinal herbs & $\begin{array}{l}\text { Memory of sickness in childhood, } \\
\text { the happiness of staying alive }\end{array}$ & Dandelion tea \\
\hline 8 & Zebrafish and hydroponic culture & Stones & Swimming in the stream in summer & Dandelion tea \\
\hline 9 & Flower basket & $\begin{array}{l}\text { Chrysanthemum morifolium, } \\
\text { Rosa hybrida }\end{array}$ & Favorite flowers and fragrance & Rose tea \\
\hline 10 & $\begin{array}{l}\text { Planting on a charcoal, } \mathrm{m} \\
\text { ini garden }\end{array}$ & Charcoal & $\begin{array}{l}\text { Reminiscences related to charcoal (straw } \\
\text { rope, soy sauce making), childbirth. }\end{array}$ & Rose tea \\
\hline
\end{tabular}

choosing magnolia tea, azalea tea, dandelion tea and rose tea as the types of tea that the subjects most wanted to drink, which was repeated 3 times to recall short-term memory.

\section{Implementation of the program}

In this study, total 10 sessions of horticultural activities were carried out once a week from March 10 to July 14, 2015 by the main therapist and researcher (horticulturalist (Level 1) of the Korean Horticultural Therapy Association). For the month of June, the program could not be carried out due to the Middle East Respiratory Syndrome (MERS). The program was carried out for 60 minutes in the program room $\left(16.5 \mathrm{~m}^{2}\right)$ at the skilled nursing facility of B Foundation.

\section{Assessment tool}

To determine the effects of horticultural activities applying reminiscent storytelling and flower tea drinking on the cognitive and emotional functions of elders with dementia, this study used the cognitive function test, self-esteem scale, elderly life satisfaction scale and ego integrity scale for assessment before and after the horticultural activities.

\section{(1) Cognitive function test: MMSE-K.}

The Korean version of MMSE (Mini Mental State Examination) made by Folstien et al. (1975) to measure cognitive abilities and translated by Kwon and Park (1989) was used in this study. MMSE-K is a measurement tool for elderly cognitive functions assessing orientation, attention, computation, language function and judgment, with the perfect score of 30 points where high scores indicate high level of cognitive functions. In this study, Cronbach's $\alpha$ for reliability was .86 . 
(2) Emotional function test

(1) Self-esteem scale

Self-esteem was measured using the scale developed by Rosenberg (1965) and adapted by Jon (1974). This scale consists of total 10 items: 5 positive and 5 negative. In this study, Cronbach's $\alpha$ for reliability was .79.

(2) Elderly life satisfaction scale

This study used the questionnaire used in the study of developing an elderly life satisfaction scale by Choi (1986). It is a self-report scale consisting of total 20 items: 6 items on life satisfaction in the past, 8 on that in the present, and 6 on that in the future. In this study, Cronbach's $\alpha$ for reliability of life satisfaction was .79.

\section{(3) Ego integrity scale}

Ego integrity was measured by the scale developed by Kim (1988) consisting of total 31 items, with higher scores indicating higher level of ego integrity. In this study, Cronbach's $\alpha$ was 0.93 .

\section{Data analysis}

Changes in the result before and after the horticultural activity program were analyzed by a nonparametric test using the SPSS Win 19.0 program, and the homogeneity testing and comparison of post-program values of the control group and the three experimental groups were carried out by the Kruskal-Wallis test. The differences in the cognitive and emotional functions within the groups were analyzed by the Wilcoxon signed-rank test, with the significance level set as $p \leq .05$.

\section{Results and Discussions}

\section{Pretest for homogeneity among groups}

Kruskal-Wallis ANOVA was used to determine the homogeneity among the control group before the program and the experimental groups with horticultural activities, flower tea drinking and both. The results showed that in all items such as cognitive functions $(p=.194)$ and emotional functions such as self-esteem $(p=.223)$, life satisfaction ( $p=.916)$, and ego integrity ( $p=.182$ ), all four groups had no significance and thereby were considered homogeneous groups in this study (Table 4).

Table 4. Test of pre treatment homogeneity among the groups.

\begin{tabular}{cccccccc}
\hline Function & Item & C & H & F & HF & $\chi^{2}$ & $p$ \\
\hline Cognitive functions & MMSE-K & $19.4 \pm 3.7$ & $16.1 \pm 5.4$ & $15.4 \pm 3.0$ & $16.7 \pm 4.2$ & 4.714 & $.194^{\mathrm{NS}}$ \\
\cline { 1 - 1 } & Self-esteem & $25.2 \pm 10.3$ & $23.9 \pm 2.7$ & $24.0 \pm 3.0$ & $24.5 \pm 3.3$ & 4.382 & $.223^{\mathrm{NS}}$ \\
Emotional functions & Life Satisfaction & $19.5 \pm 12.3$ & $19.0 \pm 7.8$ & $18.5 \pm 8.4$ & $17.7 \pm 6.4$ & 0.515 & $.916^{\mathrm{NS}}$ \\
& Ego Integrity & $95.5 \pm 37.9$ & $91.9 \pm 13.4$ & $87.9 \pm 19.9$ & $87.5 \pm 16.4$ & 4.866 & $.182^{\mathrm{NS}}$ \\
\hline
\end{tabular}

Values are presented mean \pm standard deviation.

$\mathrm{C}=$ Control group; $\mathrm{H}=$ Horticultural activity group; $\mathrm{F}=$ Flower tea group; $\mathrm{HF}=$ Horticultural activity+Flower tea group; MMSE-K, Mini-Mental State Examination.

${ }^{\mathrm{NS}}$ Non significant by kruskal-wallis ANOVA. 


\section{Pre-treatment and post-treatment changes in the group}

\section{Changes in cognitive functions (MMSE-K)}

Table 5 shows the results of using Wilcoxon signed-rank test to test the effects of the program on cognitive functions before and after for the experimental group with horticultural activities applying reminiscent storytelling, experimental group with flower tea drinking, experimental group with both, and control group. For the total average of cognitive functions, the control group had no significance with the score from 19.4 \pm 3.7 to $19.5 \pm 4.1$ ( $p=.888$ ), along with the experimental group with horticultural activities from 16.1 \pm 5.4 to $16.1 \pm 5.4(p=.492)$, and the experimental group with flower tea drinking from $15.4 \pm 3.0$ to $16.4 \pm 4.2(p=.200)$. However, the experimental group with both horticultural activities and flower tea drinking showed a significant $(p=.039)$ increase in cognitive functions from $16.7 \pm 4.2$ before to $18.0 \pm 3.5$ after.

This result was different from a study proving that dementia patients that can communicate had a more significant increase in cognitive functions in horticultural activities compared to other subjects (Yun, 2002). This may be due to the fact that the program could not be carried out for the month of June due to MERS during the experiment. However, the group carrying out flower tea drinking as well as horticultural activities applying reminiscence therapy showed improvement in cognitive functions. This is consistent with the report that reminiscence therapy is effective in improving and maintaining cognitive functions of elders with dementia (Shin, 2009). All our senses may recall memory, but olfactory sense and gustatory sense particularly serve as strong catalysts for memory (Richard, 1979), and thus the vivid visual image and olfactory effect of flower tea may have helped improve cognitive functions of dementia patients more effectively.

\section{Emotional functions}

\section{(1) Changes in self-esteem}

Table 6 shows the results of using Wilcoxon signed-rank test to determine the statistical significance of changes in

Table 5. Differences in cognitive functions between before and after the treatment by group (MMSE).

\begin{tabular}{|c|c|c|c|c|}
\hline Group & Before-test & After-test & Z & $p$ \\
\hline $\mathrm{C}$ & $19.4 \pm 3.7$ & $19.5 \pm 4.1$ & -.141 & $.888^{\mathrm{NS}}$ \\
\hline $\mathrm{H}$ & $16.1 \pm 5.4$ & $16.1 \pm 5.4$ & -.687 & $.492^{\mathrm{NS}}$ \\
\hline $\mathrm{F}$ & $15.4 \pm 3.0$ & $16.4 \pm 4.2$ & -1.282 & $.200^{\mathrm{NS}}$ \\
\hline $\mathrm{HF}$ & $16.7 \pm 4.2$ & $18.0 \pm 3.5$ & -2.060 & $.039^{*}$ \\
\hline
\end{tabular}

Values are presented mean \pm standard deviation.

$\mathrm{C}=$ Control group; $\mathrm{H}=$ Horticultural activity group; $\mathrm{F}=$ Flower tea group; $\mathrm{HF}=$ Horticultural activity+Flower tea group.

${ }^{\mathrm{NS}}$ Non significant, ${ }^{*} p<.05$ by wilcoxon signed-rank test.

Table 6. Differences in self-esteem between before and after the treatment by group.

\begin{tabular}{|c|c|c|c|c|}
\hline Group & Before-test & After-test & Z & $p$ \\
\hline $\mathrm{C}$ & $25.2 \pm 10.3$ & $24.2 \pm 9.3$ & -.914 & $.361^{\mathrm{NS}}$ \\
\hline $\mathrm{H}$ & $23.9 \pm 2.7$ & $26.3 \pm 2.1$ & -2.049 & $.040 *$ \\
\hline F & $24.0 \pm 3.0$ & $25.6 \pm 3.3$ & -2.814 & $.005^{* *}$ \\
\hline $\mathrm{HF}$ & $24.5 \pm .3 .3$ & $29.3 \pm 3.1$ & -2.254 & $.024 *$ \\
\hline
\end{tabular}

Values are presented mean \pm standard deviation.

$\mathrm{C}=$ Control group; $\mathrm{H}=$ Horticultural activity group; $\mathrm{F}=$ Flower tea group; $\mathrm{HF}=$ Horticultural activity+Flower tea group

${ }^{\mathrm{NS}}$ Non significant: ${ }^{*} p<.05, * * p<.01$ by wilcoxon signed-rank test. 
self-esteem before and after the program for the experimental group with horticultural activities applying reminiscent storytelling, experimental group with flower tea drinking, experimental group with both, and control group. The control group had no significant change with the average score from $25.2 \pm 10.3$ to $24.2 \pm 9.3$ ( $p=.361$ ). But the experimental group with horticultural activities had a significant increase from $23.9 \pm 2.7$ before to $26.3 \pm 2.1$ after $(p=.040)$, as did the experimental group with flower tea drinking from $24.0 \pm 3.0$ before to $25.6 \pm 3.3$ after $(p=.005)$. Moreover, the group with both horticultural activities and flower tea drinking also showed a significant increase of self-esteem from $24.5 \pm 3.3$ before to $29.3 \pm 3.1$ after $(p=.024)$.

This result is similar to the study proving that horticultural activities are effective in improving depression and self-esteem of elders with dementia (Lee, 1999), suggesting that self-esteem is improved as the subjects realize the pleasure of growing plants and the value of life through various horticultural activities. Furthermore, their achievement need and confidence are also improved by the output they obtain from their work, which also increased self-esteem. This is consistent with the result of the study that horticultural activities with reminiscence are effective for self-esteem of elders with dementia (Park, 2007), and also have positive effects on self-esteem of patients with chronic geriatric diseases (Kim, 2010; Lee, 2012).

\section{Changes in life satisfaction}

Table 7 shows the results of using Wilcoxon signed-rank test to determine the statistical significance of changes in life satisfaction before and after the program for the experimental group with horticultural activities applying reminiscent storytelling, experimental group with flower tea drinking, experimental group with both, and control group. The control group had no significant change with the average score between 19.5 and 18.4 ( $p=.458)$, and the experimental group with horticultural activities showed an increase in the average from $19.0 \pm 7.8$ to $21.6 \pm 6.9$ after the program, but had no significance $(p=.063)$. The experimental group with flower tea drinking showed an increase in the average from 18.5 \pm 8.4 to $18.6 \pm 10.4$, but had no significance $(p=.735)$. The experimental group with both horticultural activities and flower tea drinking showed a significant increase of life satisfaction from $17.7 \pm 6.4$ before to $28.0 \pm 6.5$ after $(p=.005)$.

This result was different from the study that patients with mild dementia in a nursing home showed improved life satisfaction as they felt interested in life through horticultural activities and such activities reduced helplessness and depression (Yoo, 2014), which may be because many of the subjects in this study already had experience participating in horticultural activities, thereby showing no change in life satisfaction. However, the group with both flower tea drinking and horticultural activities showed a remarkable effect in this study, which supports the study that the program applying warm flower tea drinking that stimulates the olfactory sense affects the limbic system that controls emotions, thereby affecting mood or behavior (Jung, 2009).

Table 7. Differences in life satisfaction between before and after the treatment by group.

\begin{tabular}{|c|c|c|c|c|}
\hline Group & Before-test & After-test & Z & $p$ \\
\hline $\mathrm{C}$ & $19.5 \pm 12.3^{z}$ & $18.4 \pm 11.2$ & -.742 & $.458^{\mathrm{NS}}$ \\
\hline $\mathrm{H}$ & $19.0 \pm 7.8$ & $21.6 \pm 6.9$ & -1.863 & $.063^{\mathrm{NS}}$ \\
\hline $\mathrm{F}$ & $18.5 \pm 8.4$ & $18.6 \pm 10.4$ & -.339 & $.735^{\mathrm{NS}}$ \\
\hline $\mathrm{HF}$ & $17.7 \pm .6 .4$ & $28.0 \pm 6.5$ & -2.810 & $.005^{* * *}$ \\
\hline
\end{tabular}

Values are presented mean \pm standard deviation.

$\mathrm{C}=$ Control group; $\mathrm{H}=$ Horticultural activity group; $\mathrm{F}=\mathrm{Flower}$ tea group; $\mathrm{HF}=$ Horticultural activity+Flower tea group

${ }^{\mathrm{NS}}$ Non significant: ${ }^{* *} p<.01$ by wilcoxon signed-rank test. 


\section{Changes in ego integrity}

Table 8 shows the results of using Wilcoxon signed-rank test to determine the statistical significance of changes in ego integrity before and after the program for the experimental group with horticultural activities applying reminiscent storytelling, experimental group with flower tea drinking, experimental group with both, and control group. The control group showed a decrease in the average from $95.5 \pm 37.9$ to $87.5 \pm 33.6$, but had no significance ( $p=.108$ ). The experimental group with horticultural activities showed a significant increase from $91.9 \pm 13.4$ to $98.0 \pm 11.5(p=.011)$. The experimental group with flower tea drinking showed an increase in the average from $87.9 \pm 19.9$ to $88.0 \pm 20.2$, but had no significance $(p=.735)$. However, the experimental group with both horticultural activities and flower tea drinking showed a significant increase from $87.5 \pm 16.4$ to $110.3 \pm 11.3(p=.005)$.

This result was similar to the study that horticultural activities applying reminiscence is effective for ego integrity of elders with chronic diseases (Kim, 2010). However, the group with flower tea drinking did not show significance because the materials like magnolia, azalea, dandelion and rose are quite familiar for subjects but may have seemed strange drinking them in the form of tea. However, the group with both horticultural activities applying reminiscent storytelling and flower tea drinking allowed the subjects to experience the growth process of plants similar to human life, thereby recalling their life overall. Moreover, they might also be able to accept the upcoming death positively with the expectation for their remaining life along with their satisfaction in the present life.

\section{Comparison of the effects of horticultural activities and flower tea drinking}

This study determined the effects of horticultural activities applying reminiscent storytelling and flower tea drinking on the cognitive and emotional functions of elders with dementia. The experimental group with horticultural activities showed a significant improvement in self-esteem and ego integrity, while that with flower tea drinking only showed an improvement in self-esteem. The group with both showed a significant improvement in all items such as cognitive functions, self-esteem, life satisfaction, and ego integrity.

The fragrance of flower tea that stimulates the olfactory sense as well as the warmth of the tea after the horticultural activities with materials and themes was conveyed through the olfactory sense and gustatory sense, comforting the elders with dementia. At the same time, the elders could recall the latent memories that helped improve cognitive and emotional functions. This can be used in a complementary sense for reminiscence of elders with dementia in the future.

\section{Conclusion}

To determine the effects of horticultural activities applying reminiscent storytelling and flower tea drinking on the

Table 8. Differences in ego integrity between before and after the treatment by group.

\begin{tabular}{|c|c|c|c|c|}
\hline Group & Before-test & After-test & Z & $p$ \\
\hline $\bar{C}$ & $95.5 \pm 37.9^{z}$ & $87.5 \pm 33.6$ & -1.605 & $.108^{\mathrm{NS}}$ \\
\hline $\mathrm{H}$ & $91.9 \pm 13.4$ & $98.0 \pm 11.5$ & -2.807 & $.011^{*}$ \\
\hline $\mathrm{F}$ & $87.9 \pm 19.9$ & $88.0 \pm 20.2$ & -2.536 & $.735^{\mathrm{NS}}$ \\
\hline $\mathrm{HF}$ & $87.5 \pm .16 .4$ & $110.3 \pm 11.3$ & -.314 & $.005^{* *}$ \\
\hline
\end{tabular}

Values are presented mean \pm standard deviation.

$\mathrm{C}=$ Control group; $\mathrm{H}=$ Horticultural activity group; $\mathrm{F}=$ Flower tea group; $\mathrm{HF}=$ Horticultural activity+Flower tea group

${ }^{\mathrm{NS}}$ Non significant: ${ }^{*} p<.05,{ }^{*} p<.01$ by wilcoxon signed-rank test. 
cognitive and emotional functions of elders with dementia, this study classified 35 elders in B Facility of D City into 4 groups and carried out 10 sessions of the program from March 10 to July 14, 2015. The result of the homogeneity test among the groups showed that the control group, experimental group with horticultural activities, experimental group with flower tea drinking, and experimental group with both horticultural activities and flower tea drinking could be considered homogeneous. For changes in cognitive functions, the control group, experimental group with horticultural activities, and experimental group with flower tea drinking had no significance, while the group with both was the only one showing a significant improvement $(p=.039)$. As for emotional functions, the control group had no significance in self-esteem, while the group with horticultural activities $(p=.040)$, group with flower tea drinking $(p=.005)$, and group with both $(p=.024)$ had significance. For life satisfaction, only the group with both had significance $(p=.005)$. For ego integrity, the control group and the group with flower tea drinking had no significance, whereas the group with horticultural activities $(p=.011)$ and the group with both had significance $(p=.005)$.

In summary of the results above, the group with both horticultural activities and flower tea drinking showed a significant improvement in all items of emotional functions and cognitive functions. Therefore, carrying out group storytelling with reminiscence and flower tea drinking along with horticultural activities that are familiar for elders may be effective for alleviating the symptoms of elders with dementia.

\section{References}

Sheridan, C.M.A. 1991. Reminiscence-uncovering a life time of memories. Elder press. San Francisco, USA.

Cho, M.K. 2008. Horticultural therapy as non-pharmacological treatment for the improvement of cognitive function and BPSD in dementia. PhD Diss., Konkuk Univ., Seoul, Korea.

Choi. S.J. 1986. A Study on the development of measuring scale of he concept of life satisfaction. J. Korean. Cult. Res. Inst. 49: 233-258.

Dailysisa. 2013. Edible flower Antioxidant function component 10 times more than vegetable, fruit. Retrieved from http://www.dailysisa.com

Folstein, M.F., S.E. Folstein, and P.R. McHugh. 1975. Mine-mental state: A practical method for grading the cognitive state of patients for the clinician. J. Psychiatr. Res. 12(3):189-198.

Hyun, S.E. 1999. Emotional Marketing Where are you from?. Marketing 33(9): 51-54.

Jon, B.J. 1974. Self-esteem: A test of its measurability. Yousei Article 11(1):107-130.

Kang, M.H. 2005. Effects of horticultural intervention program on cognition, emotion, communication and problematic behavior in older adults with Alzheimer. PhD Diss., Chungnam National Univ., Daejeon, Korea.

Kim, H.T., S.Y. Cho, and S.W. Park. 1997. Foundation of physiological psychology. Seoul, Korea: Sigma Press.

Kim, J.M. 2015. The effects of horticultural therapy based on structural recall by developmental stage on institutionalized elders'cognitive, emotional, and hand functions. Ms Thesis, Catholic Univ. Daegu, Gyeongbuk, Korea.

Kim, J.S. 1988. A study of social activities and ego integrity of the aged. PhD Diss., Ewha Womans Univ., Seoul, Korea.

Kim, M.R. 2010. Effect of horticultural therapy program with reminiscence on the elderly with chronic diseases focusing on ego integrity and self-esteem. MS Thesis, Uiduk Univ., Gyeongju, Korea.

Korean Statistical Information Services (KOSIS). 2014. Population census results. Daejeon city, Daejeon, Korea. Retrieved from http://kosis.kr

Kwon, Y.C. and J.H. Park. 1989. Korean version of mini-mental state examination (MMSE-K). part I: development of the test for the elderly. J. Korean Neuropsychiatr. Assoc. 28(1):125-135.

Lee, D.Y., J.H. Lee, Y.S. Ju, K.U. Lee, K.W. Kim, J.H. Jhoo, J.C. Yoon, J. Ha, and J.I. Woo. 2002. The prevalence of 
dementia in older people in an urban population of Korea: the Seoul study. J. Amer. Geriatr. Soc. 50(7):1233-1239. DOI: 10.1046/j.1532-5415.2002.50310.x

Lee, S.H. 1999. Effect of horticultural therapy on the changes of depression and self-esteem of demented old adults. MS Thesis, Konkuk Univ., Seoul, Korea.

Lee, H.J. 2012. Effects of horticultural therapy program using reminiscence stimulation materials on cognition and depression of elderly with dementia. MS Thesis. Dankook Univ., Cheonan, Korea.

McAnulty, S.R., L.S. McAnulty, D.C. Nieman, C.L. Dumke, J.D. Mills and P.G. Goleman. 1994. Nostalgic memories in dementia a case study. Int. J. Aging Hum. Dev. 38(3): 203-219. DOI: 10.2190/NCAJ-0G0L-VTQ4-V1L8

Ministry of Health and Welfare (MOHW). 2012. Health insurance review \& assessment service, Sejong city. Sejong, Korea. Retrieved from Http://www.mohw.go.kr/front_new/sch/index.jsp

Park, M.J. 2004. A study on the effectiveness of reminiscence therapy for the demented elderly: centered on the improvement of the cognition memory, behavior problems and the activity of daily living. MS Thesis, Mokwon Univ., Daejeon, Korea.

Park, K.A. 2007. A study on the effectiveness of group reminiscence program on the depression and cognitive ability of patients with severe. MS Thesis, Ewha Womans Univ., Seoul, Korea.

Richard, M.R. 1979. The brain. NewYork, USA: Warner books.

Sheridan, C.M.A. 1991. Reminiscence-uncovering a life time of memories. Elder press. San Francisco, USA.

Shin, S.Y. 2009. The study on the research about effect-nature of recollection method of treatment for imbecility old man's legal recognition funtion elevation. MS Thesis, Daegu Univ., Gyeongbuk, Korea.

Yoo, C.S. 2014. Determining the effects of horticultural therapy program for improving life satisfaction and reducing depression symptom of hospitalized elderly with mild dementia. MS Thesis, Konkuk Univ., Seoul, Korea.

Yun, S.Y. 2002. Effect of horticultural therapy on the improvement of recognition ability and depression in the demented old adult. MS Thesis, Catholic Univ. of Daegu, Gyeongbuk, Korea. 